\title{
Short communication: Identification and technological characterization of yeast strains isolated from samples of water buffalo Mozzarella cheese
}

\author{
M. Aponte, O. Pepe, and G. Blaiotta ${ }^{1}$ \\ Dipartimento Scienza degli Alimenti, Università degli Studi di Napoli Federico II, Via Università 100, 80055 Portici (NA), Italy
}

\begin{abstract}
Sixty yeast cultures were isolated from samples of water buffalo Mozzarella, a popular "pasta filata" cheese, originating on 16 farms located in the provinces of Salerno, Caserta, and Frosinone (Italy). Strains were identified by means of $5.8 \mathrm{~S}$ internal transcribed spacer rDNA PCR-RFLP combined with 26S rRNA gene partial sequencing and characterized for their ability to exert biochemical properties of technological interest. The recorded dominance of fermenting yeasts such as the lactose-fermenting Kluyveromyces marxianus (38.3\% of the total isolates) and the galactose-fermenting Saccharomyces cerevisiae (21.6\% of the total isolates) suggests that these yeasts contribute to the organoleptic definition of the water buffalo Mozzarella. The speciographic analysis revealed the presence of 7 other species rarely or never reported in a dairy environment belonging to the genera Pichia and Candida, whose role in Mozzarella cheese organoleptic properties need to be further investigated.
\end{abstract}

Key words: yeast community, Kluyveromyces marxianus, water buffalo Mozzarella cheese

Water buffalo Mozzarella cheese (WBMC) is a popular "pasta filata" cheese from southern Italy, manufactured in a traditional fashion from whole raw water buffalo milk using natural whey cultures as fermentation starters. This cheese is characterized by high moisture (55 to $62 \%$ ) and high fat in dry matter (>45\%), by a soft body and a juicy appearance, and by a pleasant, fresh, sour, and slightly nutty flavor. The manufacture has been described in detail in previous works (Coppola et al., 1988, 1990). Briefly, the cheese is made from whole, raw water buffalo milk by adding a natural whey culture (from the manufacture of the previous day) as a starter. After a curd-ripening phase (4.0 to $4.5 \mathrm{~h}$ at 35 to $37^{\circ} \mathrm{C}$ ), the optimal $\mathrm{pH}$ (4.9 to 5.1 )

Received November 26, 2009.

Accepted March 8, 2010.

${ }^{1}$ Corresponding author: blaiotta@unina.it is reached, and the drained curd is stretched in hot water $\left(90\right.$ to $\left.95^{\circ} \mathrm{C}\right)$.

Water buffalo Mozzarella from Campania ("Mozzarella di Bufala Campana") has been endowed with the European Product of Designated Origin (PDO) certification. The production district of this cheese is defined in its law specifications and encompasses 7 provinces across 2 regions of southern Italy (Campania and Lazio).

Previous works demonstrated that the use of unselected starters during cheese making of Mozzarella allows the development of a complex and largely undefined microbial population, whose composition may be related to the manufacturing context and to the dairy's location within the production district (Coppola et al., 2001).

The dominant microflora of cheeses including WBMC comprises lactic acid bacteria (LAB) that are responsible for acid production and the ripening process. An important input to cheese maturation is that of the secondary microbiota, mainly comprising enterococci, micrococci, nonstarter $\mathrm{LAB}$, and yeasts (Beresford et al., 2001). In recent years, yeasts have been increasingly considered as important agents in the maturation process of some cheeses (Eliskases-Lechner and Ginzinger, 1995; Mounier et al., 2005), but their contribution to cheese ripening remains unclear (Jakobsen and Narvhus, 1996; Addis et al., 2001). Recently, several studies performed on WBMC found that yeasts represent a significant part of the natural microflora, with total numbers ranging from $10^{4}$ to $10^{6} \mathrm{cfu} / \mathrm{g}$ (Coppola et al., 1988; Romano et al., 2001). In light of these observations, the aim of this study was the identification and technological characterization of yeasts isolated from samples of WBMC from 16 farms located in the provinces of Salerno (9 samples), Caserta (6 samples), and Frosinone (1 sample) in southern Italy (Table 1). Decimal dilutions of samples were performed in sterile solution of $0.9 \%$ (wt/vol) $\mathrm{NaCl}$ and inoculated in triplicate on WL nutrient agar (Oxoid, Basingstoke, UK). After incubation at $28^{\circ} \mathrm{C}$ for $72 \mathrm{~h}$, yeast colonies from counting plates were sorted based on morphology and streaked on dichloran rose-bengal chloramphenicol agar 
Table 1. Yeast species and relative distribution in the 16 sampled farms (A to Q)

\begin{tabular}{|c|c|c|c|c|c|c|c|c|c|c|c|c|}
\hline Province/farm & $\begin{array}{l}\text { Yeast, } \\
\log \mathrm{cfu} / \mathrm{g}\end{array}$ & Strains, $\mathrm{n}$ & \multicolumn{10}{|c|}{ Strain $^{1}$} \\
\hline \multicolumn{13}{|l|}{ Caserta } \\
\hline B & 2.8 & 4 & 4 & & & & & & & & & \\
\hline $\mathrm{C}$ & 1.9 & 2 & 2 & & & & & & & & & \\
\hline $\mathrm{D}$ & 2.3 & 2 & & & & 1 & & & 1 & & & \\
\hline \multicolumn{13}{|l|}{ Salerno } \\
\hline $\mathrm{G}$ & 3.9 & 6 & 1 & 5 & & & & & & & & \\
\hline $\mathrm{H}$ & 3.8 & 5 & & 1 & 1 & & & 2 & & & 1 & \\
\hline I & 2.4 & 3 & & & & & 1 & & & & 2 & \\
\hline $\mathrm{L}$ & 3.3 & 5 & 4 & & & 1 & & & & & & \\
\hline $\mathrm{M}$ & 4.1 & 5 & & 5 & & & & & & & & \\
\hline $\mathrm{N}$ & 4.3 & 4 & & 3 & & & & & & & & 1 \\
\hline $\begin{array}{l}\text { Strains, n } \\
\text { Prevalence, \% }\end{array}$ & & 60 & $\begin{array}{l}13 \\
(21.60)\end{array}$ & $\begin{array}{l}23 \\
(38.30)\end{array}$ & $\begin{array}{l}1 \\
(1.70)\end{array}$ & $\begin{array}{l}2 \\
(3.30)\end{array}$ & $\begin{array}{l}3 \\
(5.00)\end{array}$ & $\begin{array}{l}4 \\
(6.70)\end{array}$ & $\begin{array}{l}2 \\
(3.30)\end{array}$ & $\begin{array}{c}7 \\
(11.70)\end{array}$ & $\begin{array}{c}4 \\
(6.70)\end{array}$ & $\begin{array}{l}1 \\
(1.70)\end{array}$ \\
\hline
\end{tabular}

${ }^{1} S C=$ Saccharomyces cerevisiae $; K M=$ Kluyveromyces marxianus; $C B / A=$ Candida butiry/aaseri; $C P=$ Candida pararugosa CS $=$ Candida sorbophila; $C L=$ Clavispora lusitaniae $P C=$ Pichia cactophila $P B=$ Pichia barkeri; $P N=$ Pichia norvegensis $P P=P i c h i a$ pastoris.

base (Oxoid) with chloramphenicol selective supplement.

The isolated yeasts were characterized by the $5.8 \mathrm{~S}$ internal transcribed spacer (ITS) rDNA PCR-RFLP method developed by Esteve-Zarzoso et al. (1999) by using the restriction endonucleases CfoI, HinfI, and HaeIII (Promega, Madison, WI). Extraction of DNA, PCR, and RFLP analysis were performed as previously reported (Aponte et al., 2010). Representative strains of each PCR-RFLP profile were identified at the species level by sequencing of the D1/D2 region of the $26 \mathrm{~S}$ rRNA gene (Kurtzman and Robnett, 1997) according to a procedure previously described (Aponte et al., 2010).

Lipolytic activity was evaluated according to the procedure described by Fadda et al. (2004); for proteolytic activity, 2 protocols were used (Fadda et al., 2004; Gardini et al., 2006). The assimilation and fermentation of glucose, lactose, and galactose was assessed in yeast nitrogen base broth (Biolife Italiana, Milan, Italy) supplemented with $2 \%$ of each carbohydrate in test tubes containing Durham tubes. The assimilation of lactic acid and citric acid was evaluated according to Disegna et al. (1997).

Yeasts counts on WL agar ranged from 1 to $4 \mathrm{log}$ $\mathrm{cfu} / \mathrm{g}$ (Table 1), lower than those reported by other authors in WBMC (Romano et al., 2001). Sixty strains, isolated from WL agar plates seeded with the highest sample dilutions, were grouped according to the PCR-RFLP method developed by Esteve-Zarzoso et al.
(1999); results are shown in Table 2. Ten PCR products, ranging from 380 to $800 \mathrm{bp}$, were obtained (Table 2 ). Digestion using 3 restriction endonucleases ( $C f o \mathrm{I}$, HinfI, and HaeIII) presumptively confirmed the existence of 10 species, because strains characterized by the same ITS profile showed identical restriction patterns with all enzymes (Table 2). By sequencing the D1/D2 region of the $26 \mathrm{~S}$ rRNA gene, 1 strain was assigned to the species Pichia pastoris, 4 to Clavispora lusitaniae, 2 to Candida pararugosa, 3 to Candida sorbophila, 2 to Pichia cactophila, 7 to Pichia barkeri, 4 to Pichia norvegensis, 1 to Candida butiry/aaseri, 23 to Kluyveromyces marxianus, and 13 to Saccharomyces cerevisiae, confirming previous presumptive identifications obtained by restriction analysis (Table 2). In agreement with evidence obtained by Romano et al. (2001) on WBMC, $K$. marxianus and S. cerevisiae represented the dominant species, with about $38.3 \%$ and $21.6 \%$ of the total isolates, respectively. The different species were not uniformly distributed in the samples (Table 1). Twenty strains of $K$. marxianus (out of 23) were recovered in samples originating in the province of Salerno. In the sample taken in Frosinone, the sole species retrieved was P. barkeri (Table 1). Compared to data reported by Romano et al. (2001), higher biodiversity was recorded in the present study; this inconsistency can be related to the number of factories sampled and to the wider geographical area surveyed in the present work.

With emphasis on the safety assessment of dairy hemiascomycetous yeasts, the occurrence of yeast spe- 
Table 2. Result of 5.8S internal transcribed spacer (ITS) rDNA PCR-RFLP analysis by using 3 restriction endonucleases

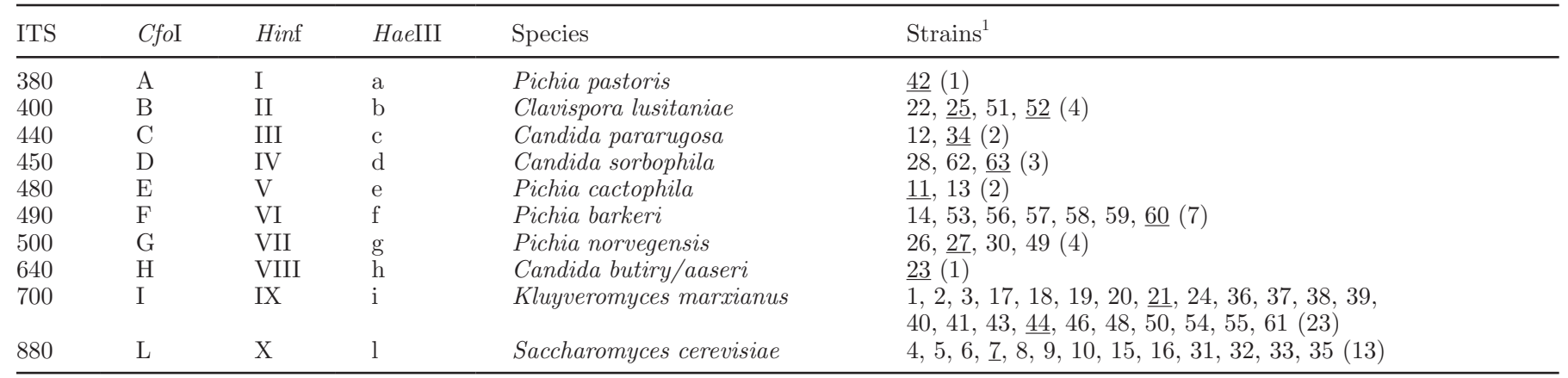

${ }^{1}$ Underlined strains were identified at species level by sequencing the D1/D2 region of the 26S rRNA gene; number of isolates in parentheses

cies in dairy environments has been reviewed recently (Jacques and Casaregola, 2008). With the exception of K. marxianus, S. cerevisiae, and Cl. lusitaniae (an emerging pathogen), none of the species retrieved in our samples was reported by Jacques and Casaregola (2008) as a usual component of the dairy microflora. Pichia barkeri has been frequently recovered in yeast communities of the cactus Pilosocereus arrabidae (Morais et al., 1994), but never in a dairy environment. In the present study, this species was found in $100 \%$ of the samples from Frosinone province. Equally, $P$. cactophila has only been associated with necrotic stems of cacti (Moraes et al., 2005). Pichia norvegensis has been isolated from humans and is considered to be an opportunistic human pathogen able to cause septicemia (Maxwell et al., 2003). Nevertheless, P. norvegensis has been recovered in other food ecosystems such as boza, a low-alcohol fermented beverage (Botes et al., 2007), and in other cheeses (Rohm et al., 1992; Westall and
Filtenborg, 1998). Similarly, there is scarce information about the normal habitat of C. pararugosa, a species phylogenetically related to Candida rugosa, which has recently been recovered from commercial red wines (Jensen et al., 2009). Kluyveromyces lactis, Debaromyces hansenii, and Yarrowia lipolytica, yeast species commonly found in dairy products (Jacques and Casaregola, 2008), were not detected in the present study. Because of their intrinsic characteristics, D. hansenii and $Y$. lipolytica usually dominate the later stages of maturation in ripened cheeses (Gardini et al., 2006); even Romano et al. (2001) did not retrieve these species in WBMC. Nevertheless, the latter authors (Romano et al., 2001) recovered both K. marxianus and K. lactis; these species are closely related and share the same biochemical activities.

One of the objectives of this study was to investigate the ability of the isolated yeasts to exert properties of industrial interest and to contribute to the desirable

Table 3. Biochemical characteristics of technological interest for yeasts isolated from natural whey culture samples

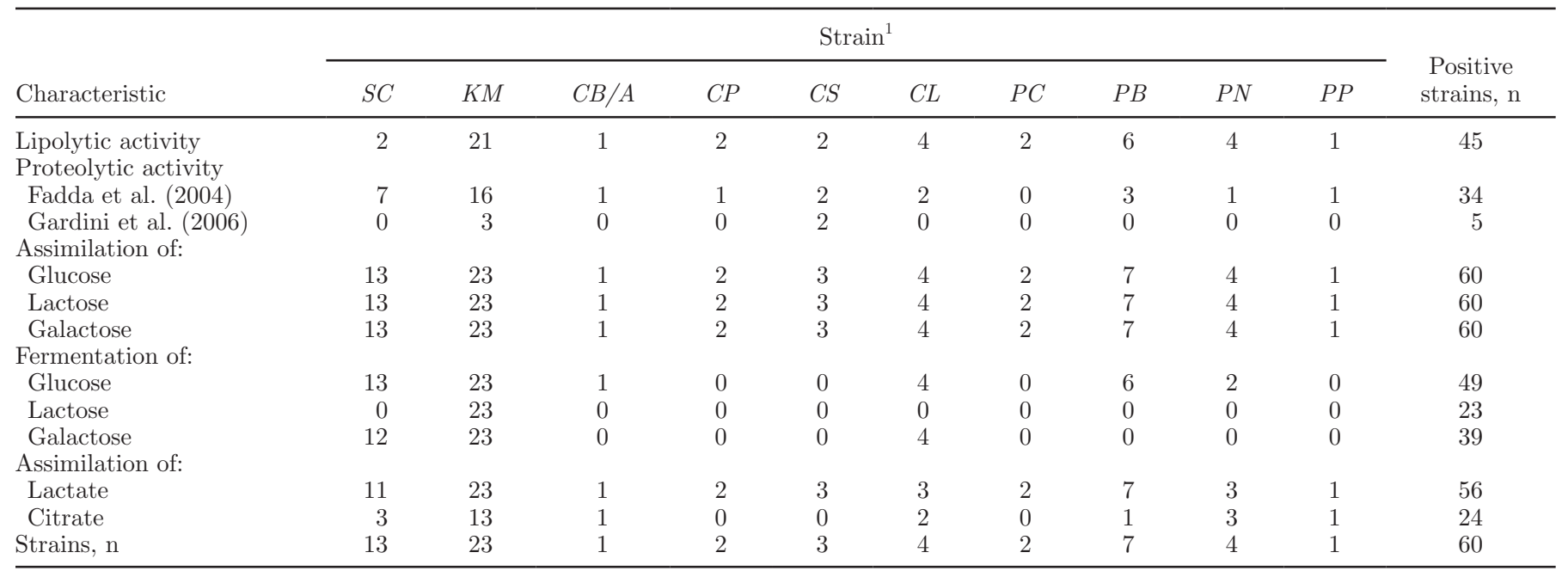

${ }^{1} S C=$ Saccharomyces cerevisiae $; K M=$ Kluyveromyces marxianus; $C B / A=$ Candida butiry $/$ aaseri CP $=$ Candida pararugosa CS $=C a n d i d a$ sorbophila; $C L=$ Clavispora lusitaniae; $P C=$ Pichia cactophila; $P B=$ Pichia barkeri; $P N=$ Pichia norvegensis; $P P=P i c h i a$ pastoris. 
organoleptic characteristics of the fermented product. All species showed the ability to assimilate glucose, lactose, and galactose, whereas the ability to ferment these carbohydrates was limited to a lower number of isolates: 49, 39, and 23 strains out of 60 were able to ferment glucose, galactose, and lactose, respectively (Table 3). The ability to ferment lactose, in agreement with current knowledge (Suleau et al., 2006; Fonseca et al., 2008), is limited to isolates of the species $K$. marxianus and $K$. lactis. The assimilation of lactate was widely held among species, whereas the assimilation of citrate was restricted to a few strains in the case of $S$. cerevisiae (3 of 13). Lipolytic activity was widespread in K. marxianus strains (22 out of 23 ), but infrequent in S. cerevisiae (2 of 13). Results regarding proteolytic activity appeared to be greatly affected by the detection method: only 5 of the total isolates were able to hydrolyze proteins according to the procedure described by Gardini et al. (2006), whereas the load of proteolytic strains increased up to 34 on plate count agar plus skim milk (Fadda et al., 2004). Only some strains of $K$. marxianus and C. sorbophila exhibited proteolytic activity with the 2 procedures used (Fadda et al., 2004; Gardini et al., 2006; Table 3). None of the unusual species recovered in the WBMC environment displayed specific activities expected from cheese yeasts (Table 3); therefore, their presence may be considered contamination. The dominance of fermenting yeast such as the lactose-fermenting $K$. marxianus and the galactose-fermenting $S$. cerevisiae could significantly contribute to the organoleptic profile of the final product by producing $\mathrm{CO}_{2}$ as well as precursors of flavoring compounds, such as ethanol, acetaldehyde, and ethyl acetate (Dahl et al., 2000).

\section{REFERENCES}

Addis, E., G. H. Fleet, J. M. Cox, D. Kolak, and T. Leung. 2001. The growth, properties and interactions of yeasts and bacteria associated with the maturation of Camembert and blue-veined cheeses. Int. J. Food Microbiol. 69:25-36.

Aponte, M., V. Ventorino, G. Blaiotta, G. Volpe, V. Farina, G. Avellone, C. M. Lanza, and G. Moschetti. 2010. Study of green Sicilian table olive fermentations through microbiological, chemical and sensory analyses. Food Microbiol. 27:162-170.

Beresford, T. P., N. A. Fitzsimons, N. L. Brennan, and T. M. Cogan. 2001. Recent advanced in cheese microbiology. Int. Dairy J. 11:259-274.

Botes, A., S. D. Todorov, J. W. von Mollendorff, A. Botha, and L. M. T. Dicks. 2007. Identification of lactic acid bacteria and yeast from boza. Process Biochem. 42:267-270.

Coppola, S., G. Blaiotta, D. Ercolini, and G. Moschetti. 2001. Molecular evaluation of microbial diversity occurring in different types of Mozzarella cheese. J. Appl. Microbiol. 90:414-420.

Coppola, S., E. Parente, S. Dumontet, and A. La Peccerella. 1988. The microflora of natural whey cultures utilized as starters in the manufacture of Mozzarella cheese from water-buffalo milk. Lait 68:295-310.
Coppola, S., F. Villani, R. Coppola, and E. Parente. 1990. Comparison of different starter systems for water-buffalo Mozzarella Cheese manufacture. Lait 70:411-423.

Dahl, S., F. K. Tavaria, and F. X. Malcata. 2000. Relationships between flavor and microbiological profiles in Serra da Estrela cheese throughout ripening. Int. Dairy J. 10:255-262.

Disegna, L., F. Rudello, and D. Spolaor. 1997. Selezione di lieviti da usare nella tecnologia dell'Asiago pressato. Latte 3:142-143.

Eliskases-Lechner, F., and W. Ginzinger. 1995. The yeast flora of surface-ripened cheeses. Milchwissenschaft 18:458-462.

Esteve-Zarzoso, B., C. Belloch, F. Uruburu, and A. Querol. 1999. Identification of yeasts by RFLP analysis of the $5.8 \mathrm{~S}$ rRNA gene and the two ribosomal internal transcribed spacers. Int. J. Syst. Bacteriol. 49:329-337.

Fadda, M. E., V. Mossa, M. B. Pisano, M. Depilano, and S. Casentino. 2004. Occurrence and characterization of yeasts isolated from artisanal Fiore Sardo cheese. Int. J. Food Microbiol. 95:51-59.

Fonseca, G. G., E. Heinzle, C. Wittmann, and A. K. Gombert. 2008 The yeast Kluyveromyces marxianus and its biotechnological potential. Appl. Microbiol. Biotechnol. 79:339-354.

Gardini, F., R. Tofalo, N. Belletti, L. Iuccia, G. Suzzi, S. Torrioni, M. E. Guerzoni, and R. Lanciotti. 2006. Characterization of yeasts involved in the ripening of Pecorino Crotonese cheese. Food Microbiol. 23:641-648.

Jacques, N., and S. Casaregola. 2008. Safety assessment of dairy microorganisms: The hemiascomycetous yeasts. Int. J. Food Microbiol. 126:321-326.

Jakobsen, M., and J. Narvhus. 1996. Yeasts and their possible beneficial and negative effects on the quality of dairy products. Int. Dairy J. 6:755-768.

Jensen, S. L., N. L. Umiker, N. Arneborg, and C. G. Edwards. 2009. Identification and characterization of Dekkera bruxellensis, Candida pararugosa, and Pichia guilliermondii isolated from commercial red wines. Food Microbiol. 26:915-921.

Kurtzman, C. P., and C. J. Robnett. 1997. Identification of clinically important ascomycetous yeasts based on nucleotide divergence in the $5 \mathrm{~V}$ end of the large-subunit $(26 \mathrm{~S})$ ribosomal DNA gene. J. Clin. Microbiol. 35:1216-1223.

Maxwell, M. J., S. A. Messer, R. J. Hollis, L. Boyken, S. Tendolkar, D. J. Diekema, and M. A. Pfaller. 2003. Evaluation for Etest method for determining fluconazole and voriconazole MICs for 279 clinical isolates of Candida species infrequently isolated from the blood. J. Clin. Microbiol. 41:1087-1090.

Moraes, M. E., C. A. Rosa, and F. M. Sene. 2005. Preliminary notes on yeasts associated with necrotic cactus stems from different localities in Brazil. Braz. J. Biol. 65:299-304.

Morais, P. B., C. A. Rosa, A. N. Hagler, and L. C. Mendonca-Hagler. 1994. Yeast communities of the cactus Pilosocereus arrabidae as resources for larval and adult stages of Drosophila serido. Antonie van Leeuwenhoek 66:313-317.

Mounier, J., R. Gelsomino, S. Goerges, M. Vancanneyt, K. Vandemeulebroecke, B. Hoste, S. Scherer, J. Swings, G. F. Fitzgerald, and T. M. Cogan. 2005. Surface microflora of four smear-ripened cheeses. Appl. Environ. Microbiol. 71:6489-6500.

Rohm, H., F. Eliskases-Lechner, and M. Bräuer. 1992. Diversity of yeasts in selected dairy products. J. Appl. Bacteriol. 72:370376.

Romano, P., A. Ricciardi, G. Salzano, and G. Suzzi. 2001. Yeasts from Water Buffalo Mozzarella, a traditional cheese of the Mediterranean area. Int. J. Food Microbiol. 69:45-51.

Suleau, A., P. Gourdon, J. Reitz-Ausseur, and S. Casaregola. 2006. Transcriptomic analysis of extensive changes in metabolic regulation in Kluyveromyces lactis strains. Eukaryot. Cell 5:13601370 .

Westall, S., and O. Filtenborg. 1998. Spoilage yeasts of decorated soft cheese packed in modified atmosphere. Food Microbiol. 15:243249 . 